https://helda.helsinki.fi

Scientific realism as a challenge to economics (and vice versa)

\title{
Mäki, Uskali
}

2011-03

Mäki , U 2011 , ' Scientific realism as a challenge to economics (and vice versa) ' , Journal of Economic Methodology, vol. 18 , no. 1 , pp. 1 - 12 .<

http://www.tandfonline.com/doi/abs/10.1080/1350178X.2011.553372\#preview >

http://hdl.handle.net/10138/39127

publishedVersion

Downloaded from Helda, University of Helsinki institutional repository.

This is an electronic reprint of the original article.

This reprint may differ from the original in pagination and typographic detail.

Please cite the original version. 
This article was downloaded by: [University of Helsinki]

On: 07 J anuary 2013, At: 06:20

Publisher: Routledge

Informa Ltd Registered in England and Wales Registered Number: 1072954 Registered office: Mortimer House, 37-41 Mortimer Street, London W1T 3J H, UK

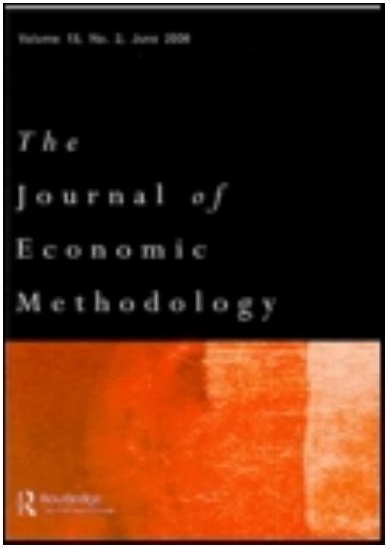

\title{
J ournal of Economic Methodology \\ Publication details, including instructions for authors and subscription information: \\ http:// www.tandfonline.com/loi/ rjec20
}

\section{Scientific realism as a challenge to economics (and vice versa)}

\author{
Uskali Mäki $^{a}$ \\ ${ }^{a}$ Department of Political and Economic Studies / Philosophy, \\ University of Helsinki, Helsinki, Finland \\ Version of record first published: 13 May 2011.
}

To cite this article: Uskali Mäki (2011): Scientific realism as a challenge to economics (and vice versa), J ournal of Economic Methodology, 18:01, 1-12

To link to this article: http:// dx. doi.org/ 10.1080/ 1350178X. 2011.553372

\section{PLEASE SCROLL DOWN FOR ARTICLE}

Full terms and conditions of use: http://www.tandfonline.com/page/terms-and-conditions This article may be used for research, teaching, and private study purposes. Any substantial or systematic reproduction, redistribution, reselling, loan, sub-licensing, systematic supply, or distribution in any form to anyone is expressly forbidden.

The publisher does not give any warranty express or implied or make any representation that the contents will be complete or accurate or up to date. The accuracy of any instructions, formulae, and drug doses should be independently verified with primary sources. The publisher shall not be liable for any loss, actions, claims, proceedings, demand, or costs or damages whatsoever or howsoever caused arising directly or indirectly in connection with or arising out of the use of this material. 


\title{
Scientific realism as a challenge to economics (and vice versa)
}

\author{
Uskali Mäki* \\ Department of Political and Economic Studies / Philosophy, University of Helsinki, Helsinki,
} Finland

\begin{abstract}
The implications of scientific realism in regard to economics depend on what one takes scientific realism to mean and on whether one lets its contents to depend on the peculiar characteristics of the discipline of economics. Here a revisionist line is adopted and scientific realism is reduced to a minimal version that is able to accommodate as large a portion of science as possible. Among other things, characterizations of minimal realism do not require, as standard formulations of scientific realism do, mind-independent existence, unobservables, and actual or likely epistemic and technological success. To accommodate economics, realism has to allow for ideas such as constitutive scienceindependence, commonsensibles, and the possibility of success. The task of turning the possibility into actual success is difficult, so requires attitudes such as humility and fallibilism as well as activities such as redesigning the institutions of inquiry.
\end{abstract}

Keywords: scientific realism; minimal realism; authentic critical realism; economics; performance of economics

\section{Introduction}

Once again, a major crisis in the economy has triggered the blame game in search of whom or what to accuse for the collapse. And again, economics is among the suspects (next to a range of others, from central bankers and other policy makers to the general human traits of greed and ignorance). Has the science of the economy failed in its tasks by failing to inform us about some fundamental facts about the real world and to alert policy makers to its risky developments? Is there something fatally wrong about its models and theories and ways of constructing and using them? Are economists just playing with toy models unconnected to the causally relevant realities of the economic world? Have they won a victory in the toy game, resulting in a defeat in the blame game?

Elsewhere, scientific realism remains the mainstream position in the philosophy of science. Its dominant varieties glorify science, its aims, capabilities and accomplishments in revealing the secrets of the world and in supporting successful technologies. Science is portrayed as the superior human achievement in acquiring true information about reality by building theories that penetrate behind the veil of appearances. It is considered the task of this philosophy of science to explain how science does the trick.

There is no similar unquestioned praise for the science of economics in the philosophy of economics or elsewhere. Economic theories and models are instead often viewed as all too unrealistic to have much to do with truth, epistemic uncertainty seems high enough to tone down bold truth claims, and the suggested policy advice does not seem to match with

*Email: uskali.maki@helsinki.fi 
the reliability of technologies supported by successful science. So scientific realism might not appear as an appropriate philosophy of economics.

Such a conclusion would be too hasty. And so would any other quick and simple claim about how scientific realism and the science of economics do or might relate to one another. We need to ask two big questions and to be prepared for complex answers:

What does scientific realism imply for economics?

What does economics imply for scientific realism? ${ }^{1}$

It is important to see that we need to ask and answer both questions next to one another, because we cannot properly answer one without answering the other. Therefore, in setting out to answer the questions, I see two notions that should be resisted: (a) Scientific realism is a well-defined doctrine in the philosophy of science with straightforward implications for economics. (b) The peculiar features of economics have implications at most for the relevance or applicability of scientific realism and not for its contents.

The exposition is in three moves. I begin with discussing versions of what I call the apparent challenge of (misunderstood) scientific realism to economics. The challenges remain apparent only largely because they are not based on dealing with the two questions together while they are based on the two views (a) and (b). I then discuss the challenge of economics to scientific realism, neglected by the apparent challenge. My revisionist argument will point out some of the consequences of making scientific realism sensitive to disciplinary peculiarities. Finally, on the basis of such a revised economics-sensitive notion of scientific realism, I will be prepared to outline some real challenges of (properly understood) scientific realism to economics.

\section{The apparent challenge of scientific realism to economics}

So what implications might scientific realism have for economics? There are a number of possible challenges depending on how scientific realism itself is being conceived. I briefly discuss three such conceptions and the associated challenges: the naive conception, the Bhaskarian conception and the conventional philosophy of science conception. What all of them share is that they tend to fix the main contents of scientific realism prior to bringing it in contact with economics.

\section{A. Naive conception of scientific realism}

The guiding principle of the naive view is that good scientific theories and models only contain true claims about real world. So realism requires models and their assumptions to be 'realistic' whereas unrealisticness in models and their assumptions imply non-realism or antirealism (e.g. instrumentalism) about them. Because economic theories and models contain plenty of falsehood and other kinds of unrealisticness, they fail the realist test. This can be qualified by suggesting that the larger the proportion of false elements in models and the larger their distance from the truth, the less appropriate it will be to endorse a realist philosophy about such models.

This line of thought is of course simplistic and misguided. Unrealisticness in theories, models and assumptions does not automatically imply non-realism as a philosophy about them. The naive view is indeed an unrefined view that may be misled by a conflation of realisticness as a property of theories and realism as a philosophical theory of theories. It may also be misled by the appearances of falsehood: models and theories surely appear to contain a lot of falsehood, but this alone does not mean that they cannot be true of some important facts in the world. 


\section{B. Bhaskarian conceptions and challenges}

There is a line of critical thinking about economics that identifies itself as 'critical' realist and has been inspired by Roy Bhaskar's early work (e.g. Bhaskar 1978). My feeling is that some of its appeal is implicitly based on attitudes akin to the naive conception sketched above, but its official arguments are different. Insofar as I have been able to determine, authors such as Lawson $(1997,1999)$ suggest that (1) 'realism' amounts to an attitude that supports two things: a concern with ontology and the theorization of causal mechanisms in open systems; and that (2) 'mainstream economics' lacks that attitude (whereas 'heterodox economics' has it), so mainstream economics fails because it is not 'realist' - because it is not interested in underlying mechanisms and because it implicitly and without reflection subscribes to a 'positivist' ontology of event regularities in closed systems. Criticism of a body of economics is hence exercised by using the criterion of compatibility with a prefixed ontology.

Two rather harsh observations can be made. First, (2) is incorrect. Much of economics has long used methods of closed systems modelling (or the method of isolation), but this should not be conflated with some closed systems ontology, let alone an ontology of 'Humean' regularities between observable events. Economists often build models that isolate simple systems from their surroundings, but they typically consider this an effective method for accessing causal mechanisms active in complex systems that are dynamically open. Moreover, they typically are realists about the mechanisms they model.

Second, (1) is unrecognizable as scientific realism from the point of view of standard philosophy of science. In this respect, things are not made easier by the tendency in the Bhaskarian literature to incorporate other ideas in the notion of realism, such as very specific ontologies of causation and of society, as well as specific methodological guidelines for doing research. Regardless of what one is to make of these specific ideas, their inclusion turns the notion of realism excessively thick (see Mäki and Oinas 2004). By doing so, it comes to pay relatively little attention to the core issues of realism proper, those related to existence and truth.

\section{Mainstream scientific realism in the philosophy of science}

In the philosophy of science, scientific realism comes in a variety of closely connected versions. A prominent line defines realism in terms of truth about unobservables and justifies it by appealing to the technological success of science. Scientific realism is right if science (or the best of science, or most of current mature science) has got its theories right about unobservables (such as electrons). And we have reason to believe that science has got its theories right because they are (predictively and technologically) successful. It would be a miracle, the argument goes, if science were successful without being true about the world (see e.g. Psillos 1999).

What seems immediately clear is that so conceived, scientific realism is not right about economics. The predictive and technological successes of economics, whatever their proportion relative to the respective failures, do not seem quite to match those of the impressively successful disciplines. So, the reasoning goes, economics has failed to capture the true and the real. Maybe it is not good or mature science, but anyway it does not invite a realist interpretation. So scientific realism is not an appropriate philosophy of economics. This is at least what one would be invited to conclude if applying the conventional ideas about scientific realism in the philosophy of science.

This popular line of reasoning has its problems even in relation to the unquestionably successful sciences, but in the case of economics and other disciplines dealing with very 
complex and hard-to-control systems, the argument seems inappropriate. In these cases, the contents of the ceteris paribus clause cannot be controlled for nor easily anticipated, which is why splendid predictive and technological success does not come about very smoothly. More strongly, it would be a miracle if it were to so come about.

\section{Hausman's challenge}

As mentioned above, standard definitions of scientific realism put it in terms of scientific theories being about unobservables (of which electron is a paradigm example). Hausman (1998) used this ingredient in his argument against the relevance of scientific realism in the philosophy of economics. Economics is not among the disciplines that postulate unobservables such as electrons, so not within the purview of scientific realism. He reaches conclusion (3) from premises (1) and (2): (3) Scientific realism is irrelevant to our concerns about economics because (2) scientific realism is a philosophical thesis about unobservables postulated by scientific theories, and (1) economic theories do not postulate such unobservables. Note that, unlike the other cases in this section, this argument does not imply anything about whether economics is a good, successful or mature scientific discipline. It simply states that scientific realism is not a good philosophy about it.

Of the two premises, (1) is fine, but (2) should be questioned. In earlier work, I had argued for (1) while suggesting that conceptions of scientific realism should be sufficiently diverse and flexible to accommodate this and other peculiar characteristics of economics and other disciplines (e.g. Mäki 1996). The very idea of unobservable subject matter is a contingent feature of many scientific theories, but it should not be a defining feature of scientific realism. There are many philosophical and methodological issues in and about economics that can be illuminated in terms of a broadly conceived scientific realism, such as that of unrealistic assumptions and the social (including rhetorical) construction of economic knowledge. ${ }^{2}$

\section{The challenge of economics to scientific realism}

In bringing a philosophy of science in contact with a scientific discipline, one may either keep the contents of the philosophy as fixed during the contact, or one may consider it dependent on what one finds out about the discipline. In dealing with a major philosophy such as scientific realism, I am strongly in favour of the latter principle (see Mäki 2005). In case the former principle is adopted, and a discrepancy emerges between a scientific realism and a specific discipline, one may draw one or both of the two conclusions: descriptively, scientific realism is inappropriate or inapplicable (because the discipline represents bad or immature or different science or some such); normatively, the discipline should change so as to improve the match with the philosophy that sets the standards. I admit such conclusions may provide interesting information, but I do not think they are the only conclusions one should consider drawing. One should also consider adjusting the philosophy rather than always taking it as intact. This section gives examples of why and how to exercise such philosophical revisionism.

In contrast to strategies such as [C] and [D] sketched in the previous section, scientific realism is not to be adopted as fixed and given from the philosophy of science literature. Among the reasons for thinking so are that the dominant formulations of scientific realism have contingent histories mostly shaped by issues in physics; they manifest excessive confidence in science and its achievements; and they suppress disciplinary diversity in ontology and epistemic performance. 
To see how scientific realism will be able to accommodate disciplines such as economics and their peculiarities, we will consider what modifications should be made in the standard formulations. Key elements in a streamlined formulation of standard scientific realism include the following:

\section{[Standard SR]}

Current (good, mature) scientific theories

are (justifiably believed to be) (approximately) true of

a realm of entities that

lies beyond the boundaries of ordinary (observable) realm of commonsense entities and exists independently of the human mind.

So you qualify as a scientific realist if you think that (current, etc.) scientific theories are true or approximately true or are justifiably believed to be so; and that these theories talk about entities that are unobservable and exist mind-independently. And you can be assured that scientific realism is right because it provides the best explanation for the uncontroversial predictive and technological success of science, and so prevents this success from appearing as a miracle.

Little examination is needed to discover that there are many great theories, fields of enquiry and scientific disciplines with respect to which scientific realism so conceived does not seem adequate. The domain of scientific realism will shrink - it comes to cover just those parts of science which are 'successful' and 'mature' and deal with mind-independent unobservables. This gives rise to what has been called piecemeal or selective realism: scientific realism becomes the right philosophy of just a selection of scientific disciplines. On the other side of this coin is a philosophical abandonment of large portions of science including economics - which are given over to non-realist philosophies of science. The diversity of science remains unacknowledged within a shared philosophical framework, and scientific realism becomes the philosophy of the privileged class of successful (physical) sciences.

One may ask why the focus of standard versions of scientific realism has been laid on the great achievements of the best of contemporary science. My suspicion is that part of the reason may be the pressing need to defend science against anti-scientific scepticism and aggression in the ongoing 'science wars' that keep threatening the cultural status and epistemic authority of science. What is notable is that economics too is a target of aggression and scepticism - but standard scientific realism will not do in defending it. What we need is a revised scientific realism, not so much to defend economics, but to deal with its philosophical issues in an effective and illuminating way.

What we need to begin with, I suggest, is a minimal formulation of scientific realism. Such a minimal realism is abstract and weak enough to encompass larger chunks of science than [Standard SR]. Minimal realism no more contains regular ingredients of standard formulations such as claiming that theories refer to mind-independent unobservables; that theories are justifiably believable as (approximately) true; that there is reason to be (uniformly) optimistic about the epistemic performance of science; that science is an uncontroversial (predictive and technological) success story and that the main or only task of the philosophy of science is that of rationally reconstructing and explaining successful scientific practice. All of these must go.

So let us start taking some steps towards minimal scientific realism. In contrast to [Standard SR], minimal realism does not require concluding that an entity Y exists. It is enough that Y might (or might not) exist. This idea finds itself in expressions such as 'Let's assume Y exists' and 'Let's try to find out whether Y exists' and 'We have (we still 
haven't) concluded that Y doesn't exist after all (that Y does exist)' and so on. What these share in common is the realist conviction that there is a fact of the matter about whether $Y$ exists or does not exist and that science has the task of finding out whether it does.

The same applies to truth. In contrast to [Standard SR], minimal realism does not require concluding that theory $\mathrm{T}$ is true about $\mathrm{Y}$. It is enough that $\mathrm{T}$ might be true (or might be false). Many expressions are compatible with this idea, including 'Let's try to find out whether $\mathrm{T}$ is true' and 'We have concluded that $\mathrm{T}$ is probably false after all' and 'There are no grounds now (and perhaps for a long time to come) to decide whether we are justified in believing that $\mathrm{T}$ is true - so let us suspend judgement' and so on. The underlying realist conviction they share is that there is a fact of the matter about whether $T$ is true or false and that science has the task of finding out whether it does.

So conceived, minimal scientific realism is able to acknowledge the diversity of science in its epistemic accomplishments and expectations. Disciplines at various stages of their development vary in their capacity to turn minimal claims about existence and truth ('might exist' and 'might be true') into stronger claims ('exists/does not exist' and 'is/is not true'). They vary in their capacity to ascribe specific degrees of justification to epistemic attitudes, including epistemic optimism. This means that there is no uniform degree of assurance with which theories are believed and with which expectations of getting them right are held. Disciplines in their specific situations differ, and minimal scientific realism is able to cover the variety.

Although [Standard SR] makes strong claims about the epistemic achievements or expectations of science, we need a less demanding scientific realism that covers cases of scientific enquiry that cannot boast about superb accomplishments or that have relatively less reason for optimism about such achievements. Such an enquiry may fall short of meeting these demands in many ways - it may be strongly hypothetical, speculative, conjectural or tentative; and it may be unreliable, erratic or uncertain - and for many reasons - it may be in the early stages of its development; it may deal with hard to access or recalcitrant subject matter; it may have stuck on misguided trajectories of enquiry; it may be characterized by chronic controversy and internal divisions and it may be under the pressure of commercial or ideological interests. Scientific realism should not abandon fields of enquiry which are more modest in their performance. It is a realist attitude to suggest that the world has its own ways and that science has the task of tracking them, with whatever actual or expected success.

This has implications for the stakes and arguments in the ongoing controversy over the credentials of economics. Instead of locating themselves in opposite philosophical camps, both friends and foes of economics should be able to share minimal scientific realism about the discipline. Economics is difficult, it deals with a very complex and recalcitrant subject matter, which is often presented as an excuse for shortcomings in its performance, perhaps suggesting that economics is doing just as well as it possibly can. On the other hand, economics is blamed by its critics to have employed misguided strategies of enquiry and mistaken theoretical frameworks, perhaps subjecting itself to ideological biases. Both sides of the controversy are fairly confident about their case, but this should not result in, respectively, realism and antirealism about economic theory. Both of them, as well as attitudes that reflect higher degrees of uncertainty, are compatible with realism or even presuppose it. In other words, rather than a philosophical conflict between a realist and antirealist interpretation of economics, we have a scientific conflict between two or more conceptions of whether economics has been and can be successful. Grounds for confidence vary from discipline to discipline as well as within disciplines.

Then we drop mind-independence from [Standard SR]. This must be done in order to accommodate the human and social sciences. Facts of mind and society are not 
mind-independent. Economics deals with preferences and expectations, strategies and interactions, demand and supply, trust and fairness, laws and conventions, agents and principals, and markets and governments. One can try to construe these items without invoking anything mental or social, but yet it seems obvious that whatever those terms are taken to refer to does not exist mind-independently and, therefore, are not in the same category with electrons, cells, continents and galaxies.

In order to have a philosophical framework that will cover all such cases, my proposal has been to replace mind-independence by notions of science-independence (Mäki 2005). Indeed, it would seem most natural that scientific realism would consider issues of existence primarily from the point of view of science-independence. Although it is not terribly difficult to think of electrons and galaxies (those things themselves, not concepts or theories of them) as existing science-independently, a special challenge arises with respect to disciplines such as economics. Indeed, isn't the economy, or at least some aspects of it, economics-dependent? Doesn't the science of economics make an impact on the economy in many ways, such as through policy advice, reflexive predictions and economics education? The importance of these possibilities is underlined by the recent debates over the 'performativity' of finance theory in shaping finance practice and the alleged effects of economics education on the behavioural dispositions of economics students (see e.g. McKenzie 2006 and Frank, Gilovich, and Regan 1993).

An effective response to this challenge is to draw a distinction between constitutive and causal (in)dependence. Minimal scientific realism will insist on constitutive scienceindependence while admitting the possibility of causal science-dependence. Much of society and the contents of our mental lives are causally dependent on science, both natural and social. Our institutions are shaped both by technologies and worldviews that are shaped by the natural and social sciences. The so-called 'self-fulfilling' and 'self-defeating' theories and predictions are in the same category. The relationship between science and what it 'shapes' in such situations is causal. A scientist puts forth a theory that manages, directly or indirectly, to inspire some relevant people, who take action guided by their changed beliefs, and this action has consequences. Agents in financial markets and economics students are the causal intermediaries between economic theories and what may appear to be consequences of these theories. Literally speaking, theories do not 'self-fulfil' or 'self-defeat' - whereas actions of people and the consequences of these actions may fulfil or defeat theories. Scientific realism should be comfortable with causal science-dependence of this kind. This does not mean that economics and other social sciences will have an easy task in deciphering this kind of increased complexity in the causal web of society of which science is a part.

What scientific realism must insist is constitutive science-independence. This would be violated if it were the case that the very act of putting forth or uttering an economic theory would thereby create or constitute an economic fact represented by that theory. Saying so makes it so - this is the principle of constitutive science-dependence that scientific realism must deny. Drawing an agreement is an example of creating a social fact of agreement by the two parties saying (signing a document that says) things such as 'I agree to deliver ... ' and 'I agree to pay...' This is performativity in its authentic sense. Unfortunately, the recent misuse of this notion in the literature - using it to refer to causal relations - has obscured the difference between causal and constitutive dependence (see Mäki 2008, 2011a). In sum, rather than requiring that the items denoted by economic theories exist mind-independently, minimal scientific realism requires them to exist constitutively science-independently.

Then we drop unobservables from [Standard SR]. The paradigm cases of unobservables in the philosophy of science literature include electrons and quarks. These are considered 
unobservable because they, given their character described by physical theory, cannot be observed by humans equipped with our standard sense apparatus. What we can observe are things such as red balloons or red-here-now, depending on the version of the doctrine. Putting forth theories that talk about electrons and quarks is to suggest a radical ontological departure from the ordinary commonsense world - to suggest a world inhabited by entirely new kinds of creatures that can only be identified in terms of these theories.

Economists also talk about unobservables, but what they usually mean are the things that are hard to observe, or that are not being observed while some other things are. But these sorts of unobservables do not suggest a realm of radically different sorts of thing, they rather usually belong to the same commonsense framework within which economic theorizing proceeds. Economics talks about things such as markets, money, prices, households, business firms, central banks, government bureaus, preferences, expectations, choice, cost, benefit, consumption, saving, investment risk, uncertainty, learning, property right, wages, taxes, debt, interest, fairness, unemployment, inflation and recession. None of these suggests a radical ontological departure from the commonsense realm of familiar things. These are among the commonsensibles that economics deals with (Mäki 1996). Commonsensibles are unlike unobservables such as electrons: they are ordinary and familiar items, or pre-theoretic in the sense that they are not dependent on scientific theory for their identification. They are unlike observables such as sense data: they are 'folk objects' that are identified by commonsense experience and conception that involve reasoning, conceptual frameworks, cultural meanings and shared interpretations. This is a 'hermeneutic moment' in economics.

Economics does not deal with its folk objects in their raw form as it were, but instead modifies them in various ways. The contestable ways of modification of commonsensibles include selection, omission, isolation, abstraction, idealization, exaggeration, projection, averaging and aggregation. These methods serve the purposes of modelling the relationships between the commonsensible items. Instead of human individuals with their rich and varying array of capacities and inclinations, economics has mostly modelled a narrowly conceived agent with fixed and idealized properties. Instead of the messy local preferences familiar to us, expected utility theory depicts a well-defined set of transitive and complete preferences. Instead of having an organizational structure with multiple actors and goals, business firms are modelled as black boxes akin to individuals with single selves and one goal. Instead of adjustment processes taking time depending on various contingencies of the situation, they can be assumed as being instantaneous. Every model makes such modifications that take the theorized commonsensibles away from the familiar folk realm.

On top of being modified, commonsensibles are also rearranged concerning their causal relationships when moving from folk conceptions to economic theories. This takes economic theory even further away from the folk understanding of economic matters. The common sense is inclined towards perceiving economic phenomena and institutions as results of intentional action by human individuals and their groups - by way of visible hand or hidden hand (conspiracy) mechanisms. Scientific economics typically represents economic phenomena and institutions as unintended consequences of human actions mediated by various invisible hand mechanisms. The non-transparency of such mechanisms motivates scientific realism (in contrast to commonsense realism), whereas to an uneducated folk conception, the scientific image may appear as counter-intuitive and paradoxical.

The folk view tends to project observations about deliberately coordinated small-scale structures (household, firm) onto larger-scale situations that are not so coordinated (market economy, international trade). Although the folk views may consider firms as monopolists with variable altruism and prices as a function of their CEOs' intentions and conspiracies, 
a version of scientific economics rather sees a merciless anonymous competitive supply and demand system. Regarding international trade, the folk view tends to see trade in terms of metaphors such as racing and warfare, recommending protectionism and favouring domestic products, whereas professional economists typically view trade as mutually beneficial exchange that is not to be restrained. So there is a clash between the two perspectives on matters of structural causation among modified commonsensibles. Minimal scientific realism does not require that new kinds of unobservables be postulated in all disciplines although it implies that the scientific picture of the world may be correct.

\section{The real challenge of scientific realism to economics}

Now that we have outlined some ingredients in a minimal conception of scientific realism that is sufficiently sensitive to the peculiarities of economics so as not to immediately expel it from the purview of scientific realism, we can change the perspective and ask what challenges such realism might pose to economics. We should ask, for example, how does science-independent existence survive reflexivity, or the causal economics-dependence of some matters of fact in the economy? One observation is that surely not everything in the economy is in such a way economics-dependent. Another is that adding another dynamic relation of causal dependence to the fabric of social causation makes the fabric more complex and economics more difficult. Given that this is probably not at all an irrelevant feature of the economic world, this can be taken to imply a call for much more attention to it by economists, other social scientists and philosophers of science. Its full implications are still to be more broadly and deeply explored, and this is likely to require interdisciplinary effort, suggesting the expansion of the theoretical and methodological horizons of economics.

Minimal realism considers theories and models as possibly true. But how can even possible truth survive all those unavoidable falsehoods in models? I have done my share on this issue elsewhere, so do not say much about it here. The important observation to make is that much of the falsehood in models is apparent only. Scientific realism should not always take the claims of science at face value, or 'literally' as many have suggested. This is because any given formulation of a theory or model and its component parts may not by itself reveal the intended or otherwise relevant contents. A larger framework of an evolving commentary on the structure and function of models by both practitioners and philosophical analysts is required to enable seeing behind the appearances (Mäki 2011b). Yet providing an illuminating commentary is not easy. History of economics is a history of misconceived beliefs about and debates over the point of models and their component parts.

Surely mere possible truths are not good enough. To begin with, the issue must be of relevant truth. It is the issue of whether truths possibly attained are relevant for some particular purposes. Relevance is a function of purposes, interests and values. This is not merely an issue of scientific realism, rather it is an issue of the design and direction of scientific enquiry, but this is based on some underlying realist principles: relevant truths are still truths. It is conceivable for economics to have been successful in capturing and accumulating truths and nothing but truths and yet to have failed miserably in anticipating and diagnosing the present crisis. The truths possibly attained may have simply been of the wrong kind, useless for the latter purposes. So the issue is not only one of pursuing truths instead of falsehoods, but importantly one of pursuing relevant truths among all possible truths. It is not always at all easy, especially in advance, to tell what sorts of truth would be relevant for a given purpose. But it is very easy and tempting indeed to go for easy-to-find 
truths regardless of whether they are relevant in regard to some given purpose. Here may be another source of the present failure: perhaps the truths that would have been helpful in preventing the crisis are difficult to discover, and perhaps economists lacked sufficient incentives that would have made them to meet the difficult challenge of looking for such hard-to-find truths.

Possible truths are not good enough for another reason. Minimal realism does not require models to be (justifiably believed to be) true, but rather that they have a chance of being true. This connects with the customary practice in economics of producing models that depict possible mechanisms and provide possible explanations. An economist typically sets out to build a model that represents a mechanism that possibly produces the stylized fact that has been established as in need of explanation. The model provides a how-possibly explanation, giving a scenario of how the explanandum phenomenon could possibly have arisen. This does not yet explain how the phenomenon has actually been generated. The model has a chance of being true of the actual causation, but to find out whether it is true of it requires different sorts of scientific effort. Economists are typically far better in providing how-possibly than how-actually explanations. They are more skilled and confident when examining the properties of the simple mini-worlds of their models than those of the real complex maxi-world and how the two worlds are related. Worse still, they sometimes mistake the model world for the real world and draw wrong conclusions for the latter. This observation might also play a role in diagnosing the present failure.

The previous paragraphs have pointed out some important sources of epistemic uncertainty. Here I would like to introduce a larger philosophical framework for dealing with these and other uncertainties by invoking what I call authentic critical realism (ACR) that is in line with a long philosophical tradition of critical realism and rather different in its focus from the Bhaskarian version of critical realism. According to ACR, ensuring a reliable epistemic access to the world is enormously difficult; cognition is the joint work by subject and object in which the subject contributes heavily; the endeavour is radically fallible; doing good science requires critical reflection of various epistemic hazards, identifying and safeguarding against sources of possible and ever-present biases and errors. This is an epistemological rather than ontological doctrine. It focuses on the complexity and proneness to hard-to-identify error of the scientific endeavour (contemporary versions include Niiniluoto 1999 and Wimsatt 2007).

I would like to make two amendments to the traditional ACR. First, attention must be paid to the various social conditions of success and failure in scientific enquiry. Second, disciplinary diversity in epistemic fortunes must be systematically acknowledged.

The early versions of ACR were too individualistic for today's tastes. Nowadays, one is expected to critically consider the possible social sources of bias and error as well as the social preconditions of success. This requires examining the institutions of economic enquiry, including various rules, conventions, traditions, path-dependencies, fashions, incentive structures, division of intellectual labour, systems of academic power, educational systems, mechanisms of consensus formation, Matthew mechanisms, larger societal pressures, academic geopolitics and other such conditions that shape the fortunes of economics. These are among the social conditions that enable and constrain enquiry and the dissemination of its results, contributing to both success and failure (depending on how one measures performance). The often-heard complaint is that the institutions of economics are not in perfect shape.

Here scientific realism can take a normative role. The first-order facts (about the economy) and the second-order facts (about economics) can be so related that in order to 
successfully pursue first-order facts, one needs not only to discover the relevant secondorder facts but to change them. Scientific realism hereby takes an axiological angle towards economics and may require redesigning its institutions. The principle guiding this sort of interventionism is: "if you want to attain relevant truths about the world, then rebuild the social conditions of your pursuit'. This is different from [Standard SR] that pays no attention to institutional conditions of enquiry, thereby implicitly presuming that they are in perfect shape for truth acquisition. Again, mere truth acquisition is insufficient, for it is the acquisition of relevant truths that matters. If it has been the case that the incentive structure and division of intellectual labour in economic enquiry have been such that few economists have found it rewarding to take on the hard task of constructing and reconstructing the big and complex picture of the contemporary financialized and globalized economy, then the present failure of the discipline has been almost unavoidable and the call for institutional redesign becomes pressing. The proportion of attention and other resources devoted to small and easy puzzles at the expense of big and hard issues should shrink.

I am not suggesting that the whole burden of explaining (as well as enhancing and preventing) success and failure should lie on the institutionally embedded epistemic practices. The ontic features of the subject matter may also play an important role. The contemporary real-world economy may be so hard to explain and control that a superb success by the science of economics would be an unlikely feat, no matter how it is institutionally organized. This is another reminder of the importance of sensitivity to disciplinary diversity. Whatever the source of failure and uncertainty, the right attitudes include humility, modesty, caution, radical fallibilism and honesty, whereas the epistemic sins include arrogance, pretension, immodesty, dogmatism and socially fabricated and enforced consensus. Failure of economics to deal with the crisis gives ample reason for avoiding such attitudes. Standard versions of scientific realism take science as a success story and encourage confidence in science's achievements, but these are not appropriate attitudes in the case of less successful disciplines. Giving up these attitudes will not compromise (minimal) realism.

\section{Conclusion}

I have outlined a conception of scientific realism that combines global and local perspectives. The global perspective is provided by minimal scientific realism. It should be sufficiently weak to accommodate as much of science and its diversity as possible. This gives a chance to economics and other less fortunate disciplines to be granted membership in the category of science that scientific realism can critically illuminate. On the other hand, minimal realism must be sufficiently strong to qualify as realism, and I believe the proposed formulations should guarantee this.

The local perspective plays two roles. First, as in the present paper, local information about a particular discipline can suggest revisions in [Standard SR] by way of dropping elements that turn out to characterize special classes of disciplines only. Second, once the minimal version of realism has been attained using the above procedure, we can start putting together specific variations of it by incorporating local disciplinary characteristics, and so thickening the thin minimalism. This brings out the disciplinary diversity that the global minimalism minimizes while allowing it.

Normatively, the global perspective encourages all of science to acquire true information about the world. Local normative scientific realism encourages maximizing epistemic successes and minimizing failures in specific fields, also by way of designing and implementing locally suitable institutional structures while taking into account the 
peculiar ontic characteristics of their subject matter. Understanding and improving the success-failure ratio in the case of economics are no exception to this.

The above can also be read as a call for empirical and institutional philosophy of science. Economics has been successful enough to be able to contribute to the contents of such an interdisciplinary enterprise.

\section{Acknowledgements}

The paper is based on the past Chairperson's address at the conference of the International Network for Economic Method, Xalapa, Mexico, 2 July 2008. The research for this paper has been conducted within TINT [Trends and Tensions of Intellectual Integration], sponsored by the Academy of Finland.

\section{Notes}

1. Note that the formulation of my title, 'Scientific realism as a challenge to economics (and vice versa)' has an audience-dependent focus - but I will be talking as much about the 'vice versa'. 'Scientific realism' is not uniformly understood - and surely not uniformly well understood across audiences and disciplines.

2. In February 1998, we organized a debate at the Erasmus Institute for Philosophy and Economics on 'Realism and its relevance for economics (and fishing)'. Hausman first presented his provocation on 'Realism as a red herring', then I defended the case for realism by talking about 'Realism as a rainbow trout'.

See Mäki (2000) which is a response to Hausman (1998); Lawson (1999) responds to Hausman on his part, not questioning premise [1]; both are followed by Hausman's rejoinders.

\section{References}

Bhaskar, R. (1978), A Realist Theory of Science, Hassocks: Harvester Press.

Frank, R., Gilovich, T., and Regan, D. (1993), 'Does Studying Economics Inhibit Cooperation?' Journal of Economic Perspectives, 7, 159-171.

Hausman, D.M. (1998), 'Problems With Realism in Economics', Economics and Philosophy, 14, $185-213$.

Lawson, T. (1997), Economics and Reality, London: Routledge.

(1999), 'What has Realism Got to Do With It?', Economics and Philosophy, 15, 269-282.

MacKenzie, D. (2006), An Engine, Not a Camera: How Financial Models Shape Markets, Cambridge, MA: MIT Press.

Mäki, U. (1996), 'Scientific Realism and Some Peculiarities of Economics', in Realism and AntiRealism in the Philosophy of Science. Boston Studies in the Philosophy of Science (Vol. 169), eds. R.S. Cohen et al., Dordrecht: Kluwer, pp. 425-445.

(2000), 'Reclaiming Relevant Realism', Journal of Economic Methodology, 7, 109-125.

(2005), 'Reglobalising Realism by Going Local, or (How) Should Our Formulations of Scientific Realism be Informed about the Sciences', Erkenntnis, 63, 231-251.

- (2008), 'Scientific Realism and Ontology', in The New Palgrave Dictionary of Economics (2nd ed., Vol. 7), London: Palgrave Macmillan, pp. 334-341.

- (2011a), 'Realism and Antirealism about Economics', in Handbook of the Philosophy of Economics, ed. U. Mäki, Amsterdam: Elsevier North-Holland.

- (2011b), 'The Truth of False Idealizations in Modelling', in Models, Simulations, and Representation, eds. P. Humphreys and C. Imbert, London: Routledge.

Mäki, U., and Oinas, P. (2004), 'The Narrow Notion of Realism in Human Geography', Environment and Planning A, 36, 1755-1776.

Niiniluto, I. (1999), Critical Scientific Realism, Oxford: Clarendon Press.

Psillos, S. (1999), Scientific Realism: How Science Tracks Truth, London: Routledge.

Wimsatt, W.C. (2007), Re-Engineering Philosophy for Limited Beings, Cambridge, MA: Harvard University Press. 